\title{
El Defensor Del Pueblo Como Problema Democrático
}

César OCHOA CARDich

\section{Consideraciones generales}

Los antecedentes históricos más relevantes del origen del Ombudsman se encuentran en Suecia. El término sueco que lo designa significa «el hombre (man) del(s) mandato(ombud)» ${ }^{1}$. Es creado en Suecia con ese nombre desde 1809. Su elección se efectúa por el Parlamento Riksdag- pero en forma indirecta, mediante una Comisión electora en la que participan representantes políticos en forma proporcional a sus votos.

En Suecia es un contralor de la administración pública en defensa del ciudadano. Posee un amplio poder para acceder a todo documento de la justicia y de la administración. En cuanto a su intervención puede actuar por propia iniciativa o por impulso de quejas o denuncias escritas, concretas y firmadas. No se obliga a que la denuncia vaya acompañada de prueba o documentos porque, en principio, el particular no dispone de las mismas, ya que están en el poder de la justicia o de la administración ${ }^{2}$.

En Suecia el Ombudsman no integra la jerarquía administrativa. Su acción como contralor no puede interferir el funcionamiento normal de la administración. En consecuencia, no interrumpe ni detiene los trámites respectivos. Investiga, solicita información a la que están obligados a proporcionarla, sin paralizar la vía judicial o la vía administrativa.

Inicialmente, en Suecia el control del Ombudsman era de legalidad.

$1 \quad$ PRAT, Julio. «El ombudsman: sus origenes, su prestigio actual y su recepción por los Derechos de Occidente» en: Revista uruguaya de Derecho Constitucional y Político, núm.9, oct-nov. 1985, Montevideo, p. 143.

$2 \quad$ Ibidem, p. 145. 
Es decir, se controlaba el cumplimiento de las leyes por el juez o el funcionario pero con carácter excepcional. Comprobada la ilegalidad, la queja se canalizaba por las vías normales competentes y salía de la esfera de la acción del Ombudsman.

Este control ha evolucionado siendo actualmente un control de mérito o de oportunidad. El control se mide en los informes periódicos que el Ombudsman presenta al Riksdag. Este control ha producido excelentes resultados porque el $R i k s d a g$ ha ido recogiendo las sugerencias del Ombudsman en leyes que han mejorado los procedimientos administrativos.

El instituto del Ombudsman se ha ido extendiendo en Europa Occidental. Así, en Alemania Federal se adoptó el denominado Ombudsman militar, previsto en la Ley Fundamental de Bonn de 1949 (Art. 45ํㅜ, inciso b). Sus atribuciones y funciones han sido cautelar el respeto de los derechos individuales y constituirse en un órgano de control parlamentario sobre las Fuerzas Armadas, pero como un órgano auxiliar del Bundestagis.

En cuanto a los caracteres generales del Ombudsman debe subrayarse que es variable en el Derecho comparado. En Argentina ha sido reconocido constitucionalmente en la reciente Constitución de 1994. En su Art. $86^{\circ}$ la Constitución argentina define al Defensor del Pueblo -siguiendo la nomenclatura española- como un órgano independiente instituído en el ámbito del Congreso de la Nación, que actuará con plena autonomía funcional, sin recibir instrucciones de ninguna autoridad. Su misión es la defensa y protección de los derechos humanos y demás derechos, garantías e intereses tutelados en esta Constitución y las leyes, ante hechos, actos u omisiones de la Administración; y el control del ejercicio de las funciones administrativas públicas.

La Constitución argentina establece que el Defensor del Pueblo es designado y removido por el Congreso con el voto de las dos terceras partes de los miembros presentes de cada una de las cámaras. La norma prevé que durará en su cargo cinco años, pudiendo ser nuevamente designado por una sola vez.

Se ha señalado por la doctrina argentina ${ }^{4}$ que el Defensor del Pueblo se ha estructurado bajo las siguientes bases:

\footnotetext{
Ibidem, p. 148.

4 Cantero, Juan Carlos. "El Defensor del Pueblo en Argentina" en: La Defensoría del Pueblo: retos y posibilidades, C.A.J., Lima, 1995, pp. 19 y ss.
} 
-Es una institución constitucional. No reviste la calidad de órgano del Gobierno, sino que constituye una institución de la República.

-Su misión es la defensa y protección de los derechos humanos de los habitantes y de los demás derechos, garantías e intereses tutelados en la Constitución, ya sea por previsión expresa o bien por la remisión a los pactos, convenciones y declaraciones internacionales previstos en la Constitución.

El objeto de su control son los actos, hechos u omisiones de la Administración, que incluye en su ámbito de competencias, a las personas jurídicas públicas no estatales que ejerzan prerrogativas públicas y las privadas prestadoras de servicios públicos.

-En particular su función de tutela ha sido prevista por la Constitución para defender los derechos relativos al ambiente, a la competencia, a los usuarios y consumidores y los derechos de incidencia colectiva Ilamados intereses difusos.

-Desarrolla sus cometidos con plena autonomía funcional, sin recibir instrucciones de ninguna autoridad.

-Tiene legitimación procesal para interponer acción de amparo en orden a tutelar los derechos relativos al ambiente, a la competencia, al consumidor, y en general los derechos de incidencia colectiva, o bien para oponerse a cualquier forma de discriminación.

-La tarea de investigación puede iniciarse a raíz de una queja del interesado, o de oficio a través de una decisión adoptada por el propio Defensor del Pueblo.

-La ley argentina prevé que el Defensor del Pueblo no puede dar curso a una queja cuando, respecto de la cuestión planteada, se encuentre pendiente resolución administrativa o judicial.

-El Defensor del Pueblo está facultado para solicitar informes escritos a los organismos o entidades investigados, los cuales están obligados a responder, bajo responsabilidad penal, en el plazo que le fije el Defensor del Pueblo y que no puede exceder los 30 días hábiles administrativos.

- Los legisladores podrán aceptar quejas de los ciudadanos, de las cuales darán traslado en forma inmediata al Defensor del Pueblo.

-El Defensor del Pueblo debe prestar especial interés a aquellos comportamientos que expresen una falla o deficiencia sistemática y general de la Administración Pública procurando prever los instrumentos que permitan eliminar o disminuir dicho carácter. 
En relación al tema del Defensor del Pueblo como problema democrático cabe la siguiente cuestión previa: ¿Es conveniente que sea el Congreso quien designe al Defensor del Pueblo? A este respecto Cantero ${ }^{5}$ precisa que sí resulta conveniente que sea el Parlamento quien designe al Defensor del Pueblo, porque siendo el objetivo fundamental de la Defensoría del Pueblo detectar las disfuncionalidades operadas en el ámbito de la Administración Pública, sería incongruente que sea el Poder Ejecutivo el que se proponga la designación del Defensor.

En Colombia el Defensor del Pueblo es creado por la Constitución de 1991, y posteriormente regulado en su organización y funcionamiento por la Ley 24 de 1992. Se le considera como un signo de identidad y de reafirmación democráticas. Así, en el régimen constitucional colombiano se considera al Defensor del Pueblo como un complemento de la protección de los derechos humanos. En ese sentido, Córdoba ${ }^{6}$ señala que:

«En el ordenamiento colombiano hay una unidad monolítica e inescindible de tres elementos: los derechos humanos, el Defensor del Pueblo y la democracia».

La función garantista del Defensor del Pueblo en Colombia no se reduce a la recepción, el trámite y la resolución de quejas. Puede promover el control judicial concreto de la constitucionalidad en caso de vulneración o amenaza de violación de un derecho fundamental, mediante el ejercicio de la acción de tutela, que corresponde a la acción de garantía del amparo en otros países.

En relación a la problemática de los derechos humanos las atribuciones del Defensor del Pueblo en Colombia corresponden a un rol de promoción y divulgación, puesto que no puede constituirse en órgano de tutela de los derechos fundamentales dado que no tiene poderes de control. En consecuencia, su misión en esta materia es esencialmente pedagógica ${ }^{7}$.

Es tal la importancia de este instituto para afianzar la democracia, que el ex-Defensor del Pueblo español Joaquín Ruiz Giménez ha expresado que:

$5 \quad$ Ibidem, p. 28.

" Córdova Trivino, Jaime. "La Defensoría del Pueblo en Colombia», en: La Defensoria del Pueblo: retos y posibilidades, C.A.J., Lima, 1995, p. 31.

7 Ibídem, p. 39. 
«... es un instrumento al servicio de la construcción de una sociedad civil, donde los valores superiores de nuestro Ordenamiento, los valores de libertad, igualdad y justicia, es decir, los valores que definen a una sociedad democrática avanzada, alcancen el máximo grado de efectividad posible» ${ }^{8}$.

La democracia como forma de gobierno debe ser defendida por efectivos controles. Uno de los instrumentos de defensa de los valores de la democracia es el Ombudsman $n^{9}$. Si la democracia debe ir adaptándose a las necesidades del mundo moderno debe caracterizarse por su flexibilidad para atender los requerimientos de la sociedad de nuestros días. En ese sentido, el Ombudsman es uno de estos instrumentos de la democracia moderna por ser una instancia ágil, sin complicados procedimientos para investigar las quejas de los ciudadanos contra los actos injustos de la Administración ${ }^{10}$.

\section{Competencias generales del Defensor del Pueblo del Perú}

La Carta peruana de 1993 lo ha diseñado como un organismo autónomo y con personería jurídica distinta del Ministerio Público (Art. 161 ${ }^{\circ}$ ). La norma jurídica fundamental declara como sus competencias:

-Defender los derechos constitucionales y fundamentales de la persona y la comunidad.

-Supervisar el cumplimiento de los deberes de la Administración estatal.

-Supervisar la prestación de los servicios públicos a la ciudadanía. En relación a sus competencias debemos precisarlas:

- La defensa de los derechos constitucionales y fundamentales de la persona y de la comunidad. A nuestro juicio, debe precisarse el sentido de la norma para no desnaturalizar la misión fundamental del Defensor del Pueblo como contralor de la Administración en colaboración con el Parlamento. En consecuencia, su misión debe entenderse como defensa de los derechos constitucionales cuando estos son afectados por la Administración Pública.

\& Ruiz-Giméniz, Joaquín, citado por Quinzio) F., Jorge. El ombudsman. El Defensor del Pueblo. Editorial Jurídica de Chile, Santiago, 1992, pp. 22-23.

9 Quinzıo F., Jorge, cit., p. 27

10 Ibidem, p. 154. 
En este sentido, consideramos que no deben crearse expectativas que pueden ser defraudadas si se perfila al Defensor del Pueblo como el protector de todos los derechos humanos cuando en esta materia su misión es fundamentalmente pedagógica. Como señala La Pérgola ${ }^{11}$ :

«... no se consigue ver cómo el Defensor pueda concretamente jugar el papel de órgano de tutela de los derechos, sin que le sean atribuídos para tal fin algunos de los poderes de control, impulso o decisión, confiados hoy a otros órganos. Por este lado se corre el riesgo de hacer un duplicado de institutos ya existentes y quién sabe si en el límite una especie de 'interpoder', que según los casos invadiría el ámbito de las autoridades judiciales o administrativas. Ahora bien, una solución tan radical perturba la disposición y, reflejamente, el equilibrio mismo de los poderes, configurado por la Constitución».

Hay que evitar que nuestro Defensor del Pueblo -como en el modelo argentino- se le pretenda asignar «impresionantes funciones que dificilmente podrá abarcar» ${ }^{12}$.

Así, los derechos que debe defender se encuentran enunciados tanto en la propia Constitución, principalmente en su artículo $2^{\circ}$, como en los tratados internacionales sobre derechos humanos que el Perú ha ratificado ${ }^{13}$.

- La supervisión del cumplimiento de los deberes de la Administración estatal frente al ciudadano. Esta competencia de la Defensoría se extiende a todo el ámbito de la Administración Pública de acuerdo al inciso 1 del Art. 9 de la Ley Orgánica de la Defensoría del Pueblo L.O.D.P. Ley 26520-. Debemos precisar el concepto de Administración Pública: la Administración Pública es un complejo orgánico integrado en el Poder Ejecutivo ${ }^{14}$.

11 La Pérciola, Antonio. "Ombudsman y Defensor del Pueblo: Apuntes para una investigación comparada» en: Revista de Estudios Politicos, núm.7, enero-febrero 1979, C.E.C., Madrid, pp. 90-91.

12 SAgues, Néstor Pedro. «Introducción a la Constitución de la Nación argentina según la reforma de 1994» en: Derecho y Sociedad, núm.1 l, Lima, enero-junio 1996, p. 72.

13 Santistivan do: Noritia, Jorge, en: "La Defensoria del Pueblo en el Perú en: Defensoria del Pueblo: Desafío y respuestas, publicación de la Defensoría del Pueblo, Lima, 1996, p. 20 .

14 Garru1) Falla, Fernando. Tratado de Derecho Administrativo, vol.I, C.E.C., Madrid, 1985 , p. 49. 
En nuestro ordenamiento el Poder Ejecutivo está conformado por sectores, cuyos responsables políticos son los ministros. Dentro de los sectores se integran: un organismo rector -el Ministerio- y organismos o instituciones públicas descentralizadas que ejecutan las políticas diseñadas por el organismo rector. En consecuencia, la competencia del Defensor del Pueblo se extiende a todos los organismos del Gobierno Central.

Asimismo, siendo nuestra estructura del Estado descentralizada la Administración Pública se extiende a los gobiernos locales y a los actuales consejos transitorios de Administración Regional.

Más complejo es determinar si las empresas del Estado forman parte de la Administración Pública. De acuerdo al Art. $7^{\circ}$ del Decreto Legislativo 757 -Ley marco para el crecimiento de la inversión privada- en ningún caso se otorgará a las empresas del Estado atribuciones de imperio o propios de la Administración Pública, con excepción de las facultades que el Estado delegue para la cobranza coactiva de tributos. Actualmente el Art. 1 de la Ley de Normas Generales de Procedimientos Administrativos -LNGPA- conceptúa a las empresas del Estado como Administración Pública sólo cuando prestan servicios públicos.

Asimismo, la precitada norma de la LNGPA preceptúa que los organismos constitucionalmente autónomos forman parte de la Administración Pública. En relación a los poderes Legislativo y Judicial no cabe lugar a dudas que no forman parte de la Administración Pública, aunque en algunos supuestos ejerzan funciones administrativas cuando, por ejemplo, se someten a las normas de Derecho Administrativo para la adquisición de bienes, suministros o servicios.

Empero, la L.O.D.P. en su Art. $14^{\circ}$ incluye expresamente dentro de su ámbito de competencia, a los organismos e instituciones de la administración de justicia que no constituyen Administración Pública. ¿Cómo puede, entonces, fundamentarse que estos organismos públicos están dentro del ámbito de supervisión de la Defensoría del Pueblo? La única salida la encontramos en el Art. $161^{\circ}$ de la Constitución que establece: «Los órganos públicos están obligados a colaborar con la Defensoría del Pueblo cuando ésta lo requiera». En consecuencia, debe interpretarse que su ámbito de competencia se extiende no sólo frente a la Administración Pública sino que incluye a todos los organismos con personería jurídica de Derecho Público que ejercen sus funciones en relación a las personas y la comunidad.

Asimismo, su competencia se extiende a personas jurídicas no estatales que ejerzan prerrogativas públicas, como los colegios profesionales por ejemplo, de conformidad con el Art. $30^{\circ}$ de L.O.D.P. 
Igualmente, no cabe lugar a dudas que su ámbito de competencia se extiende a las Fuerzas Armadas y la Policía Nacional, las mismas que forman parte de la Administración estatal y que están sometidas a su con$\operatorname{trol}^{15}$.

-La supervisión de la prestación de los servicios públicos. A este respecto, es preciso delimitar el huidizo concepto de servicio público en nuestro Derecho. Partiendo del marco constitucional, el Art. $119^{\circ}$ de la Carta de 1993 incurre en una confusión puesto que erróneamente se identifica servicio público con Administración Pública:

«La dirección y la gestión de los servicios públicos están confiados al Consejo de Ministros; y a cada ministro en los asuntos que competen a la cartera a su cargo.»

Esta norma incurre en una deficiente formulación: La dirección y gestión de la Administración Pública está confiada al Gobierno -Consejo de Ministros- y no de los servicios públicos, puesto que estos pueden ser gestionados por entidades públicas o por los particulares.

En cuanto a la definición del concepto, Garrido Falla ${ }^{16}$ propone la siguiente definición:

«Servicio Técnico prestado al público de una manera regular y constante mediante una organización de medios personales y materiales cuya titularidad pertenece a una Administración pública y bajo un régimen jurídico especial».

Cabe anotar que la concesión surge allí donde la Administración se reserva monopólicamente la titularidad de una actividad, con prohibición del libre ejercicio de la misma. La fórmula de la concesión supone la explotación del servicio -en cuanto empresa económica en manos de un particular (o concesionario) - y simultáneamente se mantiene el principio de la titularidad administrativa del servicio con carácter monopolístico ${ }^{17}$.

La Constitución de 1993 preceptúa que la iniciativa privada es libre y

15 Aran, Samuel. "La Defensoria del Pueblo: retos y limitaciones", en: Thémis, núm. 32, Lima, 1995, p. 41.

I6 Garkido Falla, Fernando, "El concepto de servicio público en Derecho Español» en: Revista de Administración Pública, núm. 135, Madrid, septiembre-diciembre 1994, p. 21. 
se ejerce en una economía social de mercado. Bajo este régimen se establece que el Estado orienta el desarrollo del país y actúa principalmente en el área de servicios públicos, entre otras. Cabe anotar que el Defensor del Pueblo cumple una función promotora de los derechos económicos de la persona y la comunidad, dentro del marco de una economía social de mercado que explícitamente reconoce un rol de orientación al Estado en el desarrollo del país.

En nuestro Derecho Público, a diferencia del español, el concepto de servicio público supone:

-En algunos casos, la acepción original: actividades económicas de interés general que han sido declaradas servicios públicos cuya titularidad es monopolio administrativo pero cuya gestión ha sido otorgada en concesión a los particulares, como transporte público, telecomunicaciones, correos, saneamiento y electricidad, etc.

-En otros supuestos, una acepción extensiva, que no supone necesariamente monopolio administrativo de la actividad ni prohibición a los particulares de desarrollar actividades sin que previamente se haya otorgado una concesión administrativa. Así, el Art. $2^{\circ}$ del Decreto Legislativo 757 comprende como servicios públicos, entre otros, a los servicios de educación, salud y recreación. Igualmente, cabe anotar que el Art. I de la LNGPA comprende dentro del concepto de entidades públicas y privadas que prestan servicios públicos a las universidades públicas y privadas.

-En otros supuestos, una acepción técnicamente errónea que confunde servicios esenciales con servicios públicos. Así, el Art. $83^{\circ}$ del Decreto Ley $\mathrm{N}^{\circ} 25593$ declara servicios públicos esenciales a:

A) Los sanitarios y de salubridad.

B) Los de limpieza y saneamiento.

C) Los de electricidad, agua y desagüe, gas y combustible.

D) Los de sepelio, y los de inhumaciones y necropsias.

E) Los de establecimientos penales.

F) Los de comunicaciones y telecomunicaciones.

G) Los de transporte.

H) Los de naturaleza estratégica o que se vinculan con la defensa o seguridad nacional.

I) Los de administración de justicia por declaración de la Corte Suprema de la República.

J) Aquellos cuya interrupción cree riesgo grave o inminente para personas o bienes. 
Cabe anotar que se está fijando el concepto de «servicio público esencial» como límite al derecho de huelga, pero erróneamente dado que si bien es cierto que todos los servicios públicos son esenciales, no todos los servicios esenciales son públicos.

De todo lo expuesto proponemos como definición de servicios públicos: todas aquellas actividades de prestación técnica que satisfacen necesidades de la comunidad, declaradas como tales mediante ley, que pueden ejercerse en un régimen de titularidad administrativa - no necesariamente exclusiva o reservada- pero con gestión privada o en un régimen de libre iniciativa con autorización o supervisión especial del Estado.

\section{Marco constitucional de la autonomía del Defensor del Pueblo}

En relación a su sistema de designación la Carta de 1993 preceptúa en su Art. $161^{\circ}$ que el Defensor del Pueblo es elegido mediante una votación de mayoría calificada de los dos tercios del número legal de miembros del Congreso. Cabe anotar que en muchos ordenamientos es elegido por asambleas legislativas, frecuentemente con mayoría absoluta o cualificada, por ejemplo, en Suecia, Finlandia, Dinamarca, Noruega, España y Argentina.

Su destitución también corresponde al Congreso, pero con el voto de los dos tercios del número legal de congresistas. Como señala Fairén ${ }^{18}$ :

"Para evitar que en la destitución de un Ombudsman interfieran movimientos políticos inestables, en algunos países se exige para su destitución un quórum parlamentario superior especial; el de dos tercios de los diputados parlamentarios (Noruega, Israel)».

En el modelo peruano goza de la prerrogativa del antejuicio político (Art. $99^{\circ}$, Const.); y no está sometido a mandato imperativo como en el modelo sueco: decide por sí mismo los problemas o casos que investigará y las acciones que seguirá, sin recibir instrucciones acerca de los asuntos de que deba ocuparse ${ }^{19}$.

\footnotetext{
18 Fairén Guillén, Víctor. "¿Posibilidad y conveniencia de introducir a los 'ombudsmännen' en los ordenamientos juridicos de naciones de habla ibérica?» en: Revista de Estudios Políticos (Nueva Epoca), núm.14, C.E.C., Madrid, marzo, abril 1980, p. 26.

1) MaIorano, Jorge Luis. "Apuntes para un debate parlamentario. El 'ombudsman' sueco» en: La Ley T.1984-C, Buenos Aires, 1984, p.840.
} 
Sobre los motivos del cese aparte de los normales: renuncia, vencimiento del plazo de designación, por muerte o incapacidad permanente, por haber sido condenado mediante resolución ejecutoria por delito doloso -el más interesante es el de «actuar con negligencia en el cumplimiento de las obligaciones y deberes del cargo» (Art. 4.4 Ley Orgánica de la Defensoría del Pueblo L.O.D.P.)-. Se trata de una mala importación legal: es una causal prevista en la legislación española. En nuestro concepto, no debió preceptuarse en la Constitución y en la L.O.D.P. el cese por remoción del Defensor del Pueblo puesto que es preferible como una garantía institucional de su autonomía propender a la inamovilidad ${ }^{20}$.

En garantía de su autonomía goza de inviolabilidad, no responde civil ni penalmente, conforme al Art. $5^{\circ}$ de L.O.D.P. Asimismo, esta norma preceptúa que el Defensor del Pueblo goza de inmunidad de arresto y proceso: No puede ser detenido ni procesado sin autorización del Congreso, salvo flagrante delito.

El cargo dura cinco años. Puede ser reelegido por una sola vez de acuerdo al Art. $2^{\circ}$ de L.O.D.P. De otro lado, el Art. $6^{\circ}$ de la Ley Orgánica precisa cuáles son sus incompatibilidades: con todo mandato representativo, cargo político, filiación política o sindical, asociación o fundación, con la carrera judicial o con el ejercicio de cualquier profesión u oficio, a excepción de la docencia universitaria. Un vacío de nuestra legislación, importación de la legislación española, es no haber previsto que perdurase durante un determinado plazo las imposibilidades para ser miembro directivo de alguna entidad sujeta a supervisión ${ }^{21}$. Asimismo, consideramos que debe ser incompatible el cargo de Defensor del Pueblo con la docencia universitaria en universidades públicas y privadas que están sujetas a su supervisión por ser entidades que prestan servicios públicos, conforme al Art. $1^{\circ}$ de la Ley de Normas Generales de Procedimientos Administrativos.

A diferencia de lo que se sostiene en España consideramos que es conveniente exigir como requisito de elegibilidad el de la idoneidad jurídico-administrativa, como ocurre en Finlandia, Suecia, Dinamarca, Noruega, Alemania y en la provincia canadiense de Quebec ${ }^{22}$.

20 Fairín Gulletiv, Victor. El Defensur del Pueblo-Ombudsman-. Centro de Estudios Constitucionales, Madrid, 1992, Tomo II, p.29.

$21 \quad$ Ibídem, Tomo I, p.507.

22 La Pérgola, Antonio, Op.cit., p.78. 


\section{Atribuciones y facultades del defensor del Pueblo.}

En cuanto a sus facultades debe puntualizarse que:

-Tiene acceso a todo tipo de documentos públicos. Esta facultad tiene base constitucional en el deber de colaboración de la Administración con la Defensoría, establecido en el Art. $161^{\circ}$ de la Carta de 1993: los órganos públicos están obligados a colaborar con la Defensoría del Pueblo cuando ésta lo requiere. Sólo quedan exceptuadas las restricciones legales, en materia de secreto judicial y de la invocación del interés superior del Estado en casos debidamente justificados como tales por los órganos competentes, únicamente en cuestiones relativas a seguridad, a la defensa nacional o a relacicones internacionales.

-No desarrolla una actividad jurisdiccional. Sus decisiones son «sugerencias» dirigidas en su caso a una autoridad administrativa interesada en el caso concreto, o al ciudadano "quejoso", pero no vinculan a la administración ${ }^{23}$.

-Su influencia reside en su autorictas, en el sentido romano del término, en una ascendencia o influjo moral asentado en la tradición que el Defensor del Pueblo debe conseguir por su permanente contacto con el pueblo y con la Administración ${ }^{24}$. Es por ello que constituye, en afortunada definición de La Pérgola, "una magistratura de simple persuasión ${ }^{25}$. Esta influencia moral sobre la Administración se manifiesta particularmente con el Informe Anual al Congreso y los informes que eventualmente presente cada vez que éste lo solicita, de conformidad con el Art. $162^{\circ}$ de la Constitución de 1993. Como señala Maiorano:

«Ese informe es, en los hechos, un cuadro de honor negativo en el cual son nombrados los funcionarios y los organismos cuya conducta negligente ha sido comprobada. Por ello la publicidad que se brinda a sus resoluciones, el who's who de la irresponsabilidad o la ineficacia en que se convierte parte de su informe anual, son medidas suficientemente disuasorias para funcionarios públicos $y$ administradores de elevada conciencia ciudadana $»^{26}$.

Fairín Gulleten, Víctor. "¿Posibilidad y conveniencia de introducir a los "umbudsmännen" en los ordenamientos jurídicos de naciones de habla ibérica?», cit., p. 27.

24 Ibídem, p. 28.

25 La ṔrgGola, Antonio, cit., p. 75.

26 Maiolano, Jorge, Op.cit., p. 842 . 
- Sus facultades de investigación son muy amplias con arreglo al inciso $l$ del Art. $9^{\circ}$ de la L.O.D.P. Inicia o prosigue de oficio o a petición de parte cualquier investigación conducente al esclarecimiento de los actos y resoluciones de la Administración Pública y sus agentes que, implicando el ejercicio ilegítimo, defectuoso, irregular, moroso, abusivo o excesivo, arbitrario o negligente de sus funciones, afecte la vigencia plena de los derechos constitucionales y fundamentales de la persona y de la comunidad.

A nuestro juicio, esta atribución de control es muy amplia, como precisa La Pérgola ${ }^{27}$ :

«En cuanto al objeto del control, éste se ejercita no sólo sobre la legalidad de los actos administrativos como está previsto en los países escandinavos, sino también sobre el ajuste de cualquier comportamiento de la administración -no importa que sea una actuación propiamente dicha o una omisión- a los parámetros de racionalidad, equidad, justicia, corrección e imparcialidad; parámetros que pueden incluso no coincidir con los criterios con que se valora la legitimidad y licitud de la conducta de la administración pública. Este tipo de control se dirige a declarar si en el supuesto en cuestión concurren los extremos de una maladministration que haya lesionado al ciudadano y pueda corregirse o repararse oportunamente después de la intervención del Ombudsman».

Si como resultado de sus investigaciones, el Defensor del Pueblo comprueba la existencia de estos comportamientos anómalos de los funcionarios administrativos o judiciales el Art. 24 de L.O.D.P. prevé que éste «se dirigirá al superior jerárquico o al órgano de la administración pública al que pertenece quien es objeto de la queja, para hacerle saber dicho resultado y sus recomendaciones al respecto. Copia del oficio será remitido directamente al afectado o al organismo". Consideramos en este sentido, una grave omisión no haber previsto expresamente como delito de desacato contra el Defensor del Pueblo, el incumplimiento injustificado del deber de cooperación con la Defensoría o la obstaculización de cualquier manera de su labor como se prevé en el ordenamiento inglés ${ }^{28}$. 
-Formula advertencias, recomendaciones, recordatorios de sus deberes legales y sugerencias para la adopción de nuevas medidas, con ocasión de sus investigaciones, pero no vinculan a la Administración Pública. Sin embargo, conforme al Art. $26^{\circ}$ de la L.O.D.P. si como consecuencia de las recomendaciones, no se adoptase una medida adecuada o la entidad administrativa no informase sobre las razones para no adoptarla, el Defensor del Pueblo podrá poner los antecedentes del asunto y las recomendaciones presentadas en conocimiento del ministro del sector o de la máxima autoridad de la respectiva entidad y, cuando corresponda, de la Contraloría General de la República.

Cabe anotar que los actos del Defensor del Pueblo son irrevisables en sede judicial y únicamente podrán ser objeto de reconsideración ante el propio Defensor, conforme al Art. $31^{\circ}$ de L.O.D.P. Este recurso impugnativo de naturaleza administrativa puede ser interpuesto por el funcionario alcanzado por la recomendación para defenderse de las acusaciones que pesan sobre él o con el administrado. Este recurso impugnativo - en la vía administrativa- le permite al Defensor modificar su opinión y dejar sin efecto la recomendación como en el modelo sueco ${ }^{29}$.

-Puede desarrollar una función mediadora que no está prevista expresamente en su Ley Orgánica, pero que estimamos puede interpretarse como comprendida dentro de su actividad de defensa del ciudadano y de supervisión de la Administración. La función mediadora de conflictos frente a las quejas del administrado es una facultad implícita que se deriva de sus atribuciones generales de "acción inmediata» para la solución de las quejas (Art. $2 \mathrm{I}^{\circ}$ L.O.D.P.) que no requieren expresa mención en su Ley Orgánica.

-Ejercita acciones de garantía constitucional de acuerdo al inciso 2 del Art. 9o de la L.O.D.P. La acción de inconstitucionalidad ante el Tribunal Constitucional contra las normas que tienen rango de ley (leyes, decretos legislativos, decretos de urgencia, reglamentos del Congreso, normas regionales de carácter general y ordenanzas municipales). Cabe anotar que es incongruente la atribución de ejercitar la acción de inconstitucionalidad contra leyes y reglamentos del Congreso, siendo el Defensor del Pueblo un Comisionado Parlamentario. Asimismo, puede interponer hábeas corpus, acción de amparo, acción de hábeas data, acción popular y acción de cumplimiento; y puede intervenir en los procesos de hábeas corpus, para coadyuvar a la defensa del presuntamente 
afectado. La legitimación procesal para el uso de las garantías constitucionales está reconocida para la protección de asuntos de interés colectivo -intereses difusos- por ejemplo, defensa del interés ecológico, interés de los consumidores, del patrimonio histórico o cultural, etc., así como a la situación de indefensión de las personas involucradas en los referidos procesos de garantías constitucionales.

- Ejercita la iniciativa legislativa. Goza de iniciativa conforme al Art. $162^{\circ}$ de la Constitución para intervenir en el proceso de formación de leyes presentando al Congreso anteproyectos de normas legales. Tiene su antecedente en el modelo sueco: los Ombudsman si al ejercer sus obligaciones supervisoras hallasen razones que aconsejen suscitar la cuestión de modificar la legislación o cualquier otra medida que el Estado debiere adoptar pueden presentar un estudio sobre la cuestión al Parlamento o al Gobierno ${ }^{30}$. Asimismo, el Art. $162^{\circ}$ de la Constitución prevé que puede proponer las medidas que faciliten el mejor cumplimiento de sus funciones. Estas medidas están dentro del ámbito normativo del Poder Ejecutivo.

- Promueve la normatividad internacional sobre derechos humanos. De conformidad con el inciso 5 del Art. $2^{\circ}$ de L.O.D.P. promueve la firma, ratificación, adhesión y efectiva difusión de los tratados internacionales sobre derechos humanos.

- Organizar y administrar el Registro Nacional de Detenidos y Sentenciados a Pena Privativa de Libertad Efectiva, por mandato del inciso 6 del Art. $9^{9}$ de la L.O.D.P.

\section{La Defensoría del Pueblo y la institucionalidad democrática}

En el modelo peruano debe resaltarse la importancia de la relación entre el Defensor del Pueblo y el problema de la gobernabiblidad democrática del país.

Como recuerda Samuel Abad ${ }^{31}$, durante el debate en el Pleno del Congreso se sostuvo que el proyecto de Ley Orgánica de la Defensoría del Pueblo convertiría al Defensor en un «superpoder», "un gran inquisidor», generaría una enorme burocracia, afectaría la defensa y la seguridad nacional y convertiría al Perú en un país ingobernable. 
A este respecto, esta tesis negativa de la necesidad de la Defensoría del Pueblo ha sido refutada por Abad con los siguientes argumentos ${ }^{32}$ :

-El Defensor no es un «superpoder». Está sujeto al control funcional del Congreso quien podrá cesarlo si considera su conducta como negligente. Asimismo, el Congreso decidirá si le asigna el presupuesto que solicita.

-Su labor no afecta a la seguridad o defensa nacional. El Art. $17^{\circ}$ de la Ley Orgánica de la Defensoría del Pueblo establece restricciones al accionar del Defensor en casos debidamente justificados como tales por los órganos competentes, únicamente en cuestiones relativas a la seguridad, a la defensa nacional o a relaciones internacionales. Asimismo, se precisa en la norma que la decisión de no remitir o exhibir documentos por las razones aludidas deberá ser acordada por el jefe del sector respectivo en concordancia con los ministros de Defensa, del Interior, o de Relaciones Exteriores según el caso de lo cual se extenderá certificación que será remitida al Defensor del Pueblo.

Resultan particularmente graves las restricciones en materia de seguridad y defensa nacional puesto que se han erigido para evitar el acceso a los cuarteles cuando eventualmente se vulneren derechos humanos ${ }^{33}$. Cabe anotar que en el Derecho Comparado, el Ombudsman sueco incluyó la figura del Ombudsman militar (militieombudsman) desde 1915 hasta 1967. Tras las sucesivas reformas de la institución en su país de origen se ha asignado a uno de los ombudsmännen la supervisión de las Fuerzas Armadas y las cuestiones civiles dentro de su ámbito de competencia $^{34}$. Asimismo, cabe subrayar el antecedente del Ombudsman militar alemán en su rol de contralor parlamentario sobre las Fuerzas Armadas.

En consecuencia, siguiendo los antecedentes del Derecho Comparado, el Defensor del Pueblo peruano debe tener dentro de su ámbito de competencia la supervisión de las Fuerzas Armadas, así como al Servicio de Inteligencia Nacional ${ }^{35}$. En una sociedad democrática el Ombudsman

\footnotetext{
$32 \quad$ Ibidem, p. 39-40.

$33 \quad$ Ibidem, p. 40.

34 Maiorano, Jorge, Op.cit., p. 839.

35 En el modelo sueco, Víctor. El Defensor del Pueblo-Ombudsman-; cit. Tomo I, p.273, cita un caso en que el Ombudsman declaró que el Servicio de Inteligencia sueco había cometido delito de violación de domicilio por colocar aparatos de escucha en el domicilio de una señora extranjera.
} 
tiene pleno acceso a los establecimientos militares o de la Defensa Nacional, en el marco de sus atribuciones inspectoras.

A este respecto, debe precisarse que el Art. $16^{\circ}$ de L.O.D.P. dice que las autoridades, funcionarios y servidores de los organismos públicos proporcionarán las informaciones solicitadas por el Defensor del Pueblo, y facilitarán las inspecciones que éste disponga a los servicios públicos, establecimientos de la Policía Nacional y penitenciarios y entidades sometidas a su control. No cabe la menor duda que este control incluye a las Fuerzas Armadas y a los organismos del Sistema de Defensa Nacional que forman parte de la administración estatal, incluyendo el Servicio de Inteligencia Nacional.

Finalmente, sobre el rol del Defensor del Pueblo en una sociedad democrática consideramos muy precisas las palabras del diputado español Alzaga quien en sesión plenaria de 11 de noviembre de 1980 dijo:

«... es absolutamente fundamental que el Defensor del Pueblo sea un auténtico colaborador de la Administración, que ha de lograr que esa Administración que tiene una carga de inercia histórica e importante en cuanto a ciertos métodos de funcionamiento, alcance en la nueva situación democrática una mayor predisposición, una mayor preocupación por el respeto de los derechos y las libertades de los ciudadanos y esto no es incompatible, sino perfectamente coherente, con que la labor del Defensor del Pueblo, a la par, busque y logre que la Administración pública, las administraciones públicas, sean cada vez más funcionales. Sólo así contribuirá la nueva institución al mayor prestigio del poder político ante la opinión pública. Esto es tanto como decir que contribuirá a la legitimación cotidiana del Estado es una pieza básica para consolidar el sistema político democrático que estamos todos, pieza a pieza, construyendo» ${ }^{36}$. Estas mismas palabras son aplicables, sin la menor duda, al actual proceso peruano de construcción de una institucionalidad democrática. 